\title{
Preduodenal Portal Vein (PDPV): A Very Rare Cause of Duodenum Obstruction
}

\author{
Beatriz Dinamarco1, Elsner Gonzaga1, Willy Marcus França2², Pedro Luis Escher Parron'1, \\ Patrícia Junqueira Mais Soares ${ }^{1}$ \\ ${ }^{1}$ Medical Science and Health Faculty, PUC/SP (FCMS, PUC/SP), Sorocaba, Brazil \\ ${ }^{2}$ Pediatric Surgeon, the Medical Science and Health Faculty, PUC/SP, the Laboratory of Surgery Technique and Experimental \\ Surgery of FCMS, PUC/SP, Sorocaba, Brazil \\ Email: *willy@drwilly.com.br
}

How to cite this paper: Dinamarco, B., Gonzaga, E., França, W.M., Parron, P.L.E. and Soares, P.J.M. (2017) Preduodenal Portal Vein (PDPV): A Very Rare Cause of Duodenum Obstruction. Surgical Science, 8, 493-498.

https://doi.org/10.4236/ss.2017.812055

Received: October 10, 2017

Accepted: December 1, 2017

Published: December 4, 2017

Copyright ( 92017 by authors and Scientific Research Publishing Inc. This work is licensed under the Creative Commons Attribution International License (CC BY 4.0).

http://creativecommons.org/licenses/by/4.0/

(c) (i) Open Access

\begin{abstract}
Congenital duodenal obstruction (CDO) is one of the most common anomalies presented in the neonatal period of intestinal obstruction, with an incidence of 1:10,000, and Preduodenal Portal Vein (PDPV) is a rare extrinsic cause of CDO. PDPV leads to CDO with a persistent vomiting, impairment of the oral feeding and weight loss, but other publications state an asymptomatic disease that may requires late surgical correction. Prenatal diagnosis of CDO, including PDPV, is evidenced by association of polyhydramnios with a dilated fluid-filled gastric and duodenum and a double-bobble image in the ultrasonography and permits a proper management of associated malformation, delivery, surgery and allows family counseling. PDPV is commonly associated to other intestinal obstruction such as extrinsic (annular pancreas, adhesive bands, malrotation, peritoneal bands, intestinal duplication), and intrinsic (atresia, web and stenosis), and also associated with cardiovascular anomalies, situs inversus, Down's syndrome and polysplenia. This is full term 5 days old newborn, $2865 \mathrm{~g}$ girl, without prenatal diagnosis of CDO. It was not still established PDPV until surgery procedure such as Duodenoduodenostomy (Diamond-Shape) and can guide Paediatric Surgeons that face high intestinal obstruction in the neonate with or without prenatal diagnosis. In the ambulatory follow up after 4 months, baby has developed very well, in breast-feeding associated with formula-feeding with a normal weight gain (average of $550 \mathrm{~g} / \mathrm{month}$ ).
\end{abstract}

\section{Keywords}

Duodenal Obstruction, Preduodenal Portal Vein, Polysplenia, Ultrasonography

\section{Introduction}

Congenital duodenal obstruction (CDO) is one of the most common anomalies 
that is presented in the neonatal period in almost $50 \%$ of all cases of the newborn intestinal obstruction, with an incidence of 1:10,000 [1] [2]. Preduodenal Portal Vein (PDPV) is reported such as a very rare anomaly that causes CDO [3] [4]. In 25-year retrospective study Kouwenberg M et al., 2008, reported 5 patients with PDPV [5]. Chen QJ et al., 2014, reported only 2 cases of PDPV in 287 newborns (0.7\%) in 10 years (2003-12) [6].

PDPV is described as a rare condition that happens in the neonatal period that leads to $\mathrm{CDO}$ causing persistent vomiting, impairment of the oral feeding and weight loss [6]. On the other hand, other publications state a generally asymptomatic disease and may lead to intestinal obstruction as well, requiring late surgical correction [7] [8] [9].

Prenatal diagnosis of CDO, including PDPV, is evidenced by association of polyhydramnios with a dilated fluid-filled gastric and duodenum and appearing as double-bobble image on ultrasonography [10] and provides important data for a proper management such as: search of associated malformation, plan of the delivery and neonatal surgery and allowing for better family counseling [11]. Other studies present that $\mathrm{CDO}$ can affect pre-operative complication, time for the surgery, delay of oral feeding and time of hospital stay, but mortality or morbidity are not affected [12].

$\mathrm{CDO}$ is commonly associated with other mechanisms of intestinal obstruction such as extrinsic (annular pancreas, adhesive bands, malrotation, peritoneal bands, intestinal duplication, including PDPV), and intrinsic (atresia, web and stenosis) [2] [13]. PDPV is also associated to cardiovascular anomalies, situs inversus, Down's syndrome and polysplenia [4] [5] [14].

This is a 5 days old newborn without prenatal diagnosis of CDO. Diagnosis was not still established PDPV until surgery and can guide specially Paediatric Surgeons that face high intestinal obstruction in the neonate with or without prenatal diagnosis [5]. An informed consent from the family was signed in the second month of follow-up and it is in the baby's chart at the hospital.

\section{Case Report}

A full term ( $38^{\text {th }}$ week of gestation) 5 days old newborn with a $2865 \mathrm{~g}$ girl. At the delivery room Neonatologist has sucked up to $55 \mathrm{ml}$ from gastric tube suggesting CDO. On the first day of life, the patient eliminated meconium and proceeds with vomiting after feeding with bile stained content.

On the second day of life, there was a persistent vomiting even with an open gastric tube and the baby was submitted to a radiologic procedure that showed an enlarging of the gastric image and a second at the duodenum site, strongly suggesting a double bobble image of $\mathrm{CDO}$ (Figure 1).

The newborn was submitted to a laparotomy in the $5^{\text {th }}$ day of life, through a right upper transversal incision and confirmed CDO with a large Gastric and Duodenum dilatation. At the beginning it was supposed to be an intrinsic cause of obstruction, because it was not identified an annular pancreas or even a large 


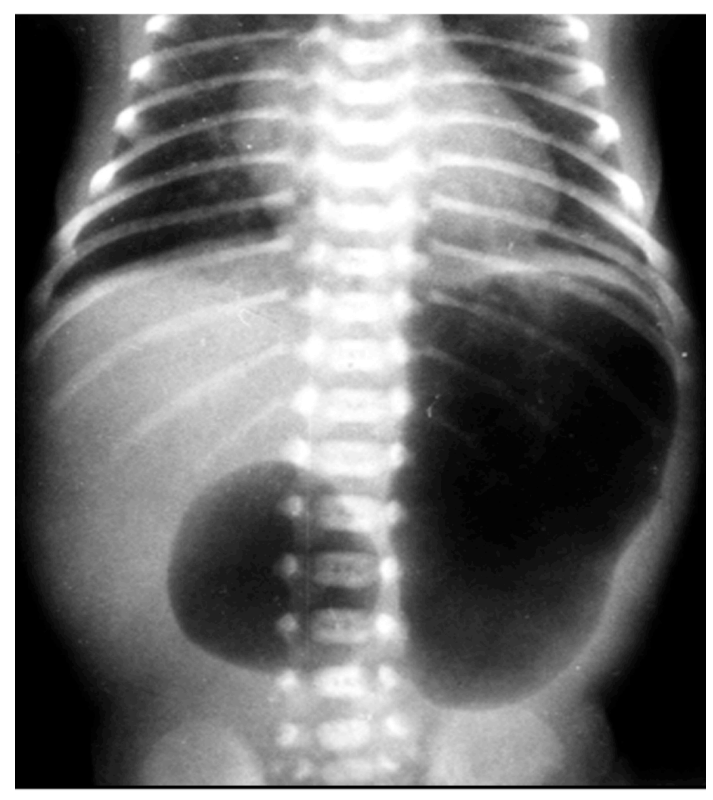

Figure 1. Showed an enlarging of the gastric image and a second one at the duodenum site, strongly suggesting a double-bobble image of CDO.

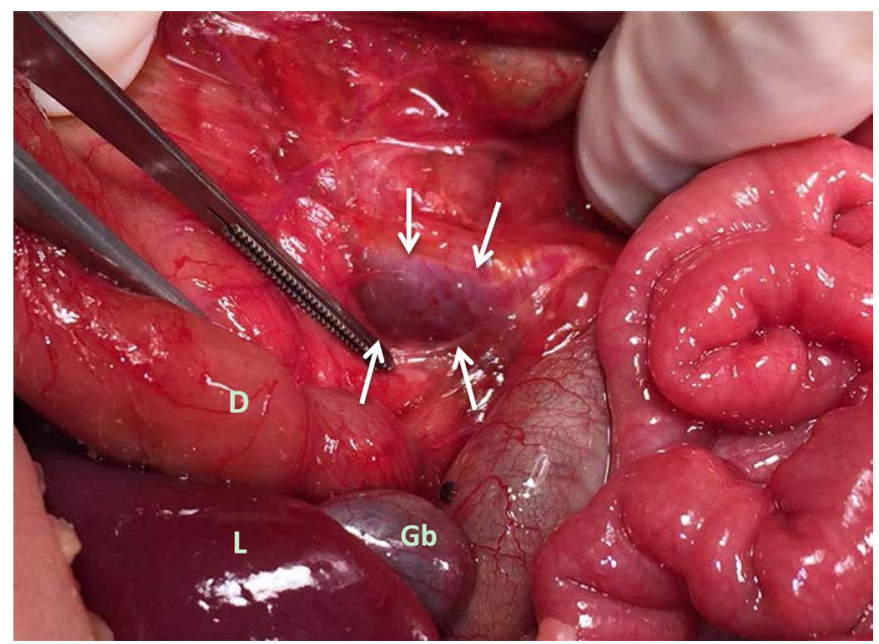

Figure 2. White arrows show PDPV obstructing Duodenum (D). Below D it is the Liver (L), Gallblader (Gb). Tweezer is over the duodenum mesentery close to the duodenum narrowing behind PDPV.

Ladd's band. But following duodenum narrowing and obstruction towards its $3^{\text {rd }}$ portion it was identified a PDPV causing complete obstruction (Figure 2) [14] [15]. It was associated with malrotation of the Colon but no polysplenia.

Correction was performed with a duodenoduodenostomy anastomosis through a Diamond-Shape suture with 5-0 polipropilene string [1] [14].

The baby was discharge from hospital in the $16^{\text {th }}$ day after surgery, in breast-feeding associated with formula-feeding (50\% - 50\%), and she had a weight gain of $160 \mathrm{~g}$ in almost 2 weeks. Four months of age, she's developed very well, scar with a very good aspect, keeping a mix of breast and formula-feeding (30\% - 70\% in volume of each, respectively). She has got $2.030 \mathrm{~g}$ in this period. 


\section{Discussion}

$\mathrm{CDO}$ is one of the most common anomalies in the neonatal period that causes high intestinal obstruction [1] [6]. Despite CDO frequently leads to persistent vomiting, impairment of the oral feeding and weight loss [6], other studies state asymptomatic or symptomless CDO requiring late surgical correction [2] [7]. Despite no consensus has yet been reached regarding its exact mechanism [16], extrinsic and intrinsic presentations of $\mathrm{CDO}$ have been reported in the literature [2] [13], other mechanisms such as isolated familial annular pancreas, suggesting a genetic basis for the CDO development [16], intrinsic obstruction such as food impact in a congenital membranous duodenal stenosis was recognized upon endoscopy have been published recently [17].

Preduodenal Portal Vein (PDPV) is reported such as a very rare anomaly that causes CDO and associated with duodenal stenosis and Down syndrome, differently of the presented case that didn't present any malformations associated [3] [4]. Kouwenberg M et al., 2008, reported 5 patients with PDPV [5] in a 25 years retrospective study. Chen QJ et al., 2014, reported only 2 cases of PDPV in 287 newborns $(0.7 \%)$ in 10 years (2003-12) [6]. Surgical correction was similar to the literature that is duodenoduodenostomy anastomosis through a Diamond-Shape [3] [6] [8] [18].

In this report, a term neonate had a good birth weight and presented high intestinal obstruction symptoms since he was born, while literature states $20 \%$ of premature and delayed presentation [6]. Literature states malrotation in 31\%-60\% of the cases, such as in this neonate [1] [6]. There were no other associated anomalies.

Prenatal diagnosis of CDO provides important data for a proper management for the neonatal team and helps to prepare a better surgery conditions, besides permit family counseling 11 . Other study states that complication is significantly small in the prenatal diagnosis group of CDO when compared with the group without prenatal diagnosis, but it didn't affect mortality or morbidity in both of them [12]. Meanwhile, some authors state that "timely diagnosis and aggressive surgery are key" to improve prognosis [6].

In conclusion, a complex entity with various etiologies and concomitante disorders [6], we strongly recommend that in a presence of a newborn with CDO, with prenatal polyhydramnios and with the described symptoms, double-bobble image at the X-ray, Pediatric Surgeons investigate PDPV if intrinsic or extrinsic cause for CDO isn't identified. A prenatal detailed evaluation should be done in all suspected cases with those signs of $\mathrm{CDO}$, searching for associated cardiovascular and other anomalies, due to preparing all the medical team and program an adequate family counseling.

\section{References}

[1] Bailey, P.V., Tracy, T.F., Connors, R.H., Mooney, D.P., Lewis, J.E. and Weber, T.R. (1993) Congenital Duodenal Obstruction: A 32-Year Review. Journal of Pediatric 
Surgery, 28, 92-95. https://doi.org/10.1016/S0022-3468(05)80364-1

[2] Gianino, P., Castagno, E., Grassino, E.C., Guidi, C. and Mostert, M. (2010) Late and Unusual Onset of Congenital Duodenal Obstruction Due to Combination Lesion. Minerva Pediatrica, 62, 223-225.

[3] Fernandes, E.T., Burton, E.M., Hixson, S.D. and Hollabaugh, R.S. (1990) Preduodenal Portal Vein: Surgery and radiographic appearance. Journal of Pediatric Surgery, 25, 1270-1272. https://doi.org/10.1016/0022-3468(90)90528-H

[4] Mordehai, J., Cohen, Z., Kurzbart, E. and Mares, A.J. (2002) Preduodenal Portal Vein Causing Duodenal Obstruction Associated with Situs Inversus, Intestinal Malrotation, and Polysplenia: A Case Report. Journal of Pediatric Surgery, 37, 1-3. https://doi.org/10.1053/jpsu.2002.31643

[5] Kouwenbertg, M, Kapusta, L., van der Staak, F.H. and Severijnen, R.S. (2008) Preduodenal Portal Vein and Malrotation: What Causes the Obstruction? European Journal of Pediatric Surgery, 18, 153-155. https://doi.org/10.1055/s-2008-1038647

[6] Chen, Q.J., Gao, Z.G., Tou, J.F., Qian, Y.Z., Xiong, Q.X. and Shu, Q. (2014) Congenital Duodenal Obstruction in Neonates: A Decade's Experience from One Center. World Journal of Pediatrics, 10, 238-244. https://doi.org/10.1007/s12519-014-0499-4

[7] Georgacopulo, P. and Vigi, V. (1980) Duodenal Obstruction Due to a Preduodenal Portal Vein in a Newborn. Journal of Pediatric Surgery, 15, 339-340. https://doi.org/10.1016/S0022-3468(80)80152-7

[8] Singal, A.K., Bamu, C., Paul, S. and Matthai, J. (2009) Preduodenual Portal Vein in Association with Midgut Malrotarion and Duodenal Web-Triple Anomaly? Journal of Pediatric Surgery, 44, e5-e7. https://doi.org/10.1016/j.jpedsurg.2008.10.075

[9] Talus, H., Roohipur, R., Depaz, H. and Adu, A.K. (2006) Preduodenal Portal Vein Causing Duodenal Obstruction in an Adult. Journal of the American College of Surgeons, 202, 552-553. https://doi.org/10.1016/j.jamcollsurg.2005.08.022

[10] Pathak, D. and Sarin, Y.K. (2006) Congenital Duodenal Obstruction Due to a Preduodenal Portal Vein. Indian Journal of Pediatrics, 73, 423-425. https://doi.org/10.1007/BF02758567

[11] Bittencourt, D.G., Bartini, R., Marba, S. and Sbragia, L. (2004) Congenital Duodenal Obstruction: Does Prenatal Diagnosis Improve the Outcome? Pediatric Surgery International, 20, 582-585. https://doi.org/10.1007/s00383-004-1235-2

[12] Savran, B., Adigüzel, Ü., Yüksel, K.B., Seven, A., Fazli, O., Kabil Kucur, S. and Öztürk Gözükara, I. (2016) The Importance of Antenatal Diagnosis of Congenital Duodenal Obstruction. Irish Journal of Medical Science, 185, 695-698. https://doi.org/10.1007/s11845-015-1345-y

[13] Tovar, J.A., Benavent, M., Bachiller, C. and Díez-Pardo, J.A. (1978) Preduodenal Portal Vein. Anales Espanoles De Pediatria, 11, 565-574.

[14] Golombek, S., Bilgi, J. and Ukabiala, O. (1995) Duodenal Web with Preduodenal Portal Vein. Iowa Med., 85, 246-249.

[15] Choi, S.O. and Park, W.H. (1995) Preduodenal Portal Vein: A Cause of Prenatally Diagnosed Duodenal Obstruction. Journal of Pediatric Surgery, 30, 1521-1522. https://doi.org/10.1016/0022-3468(95)90430-1

[16] Etienne, D., John, A., Menias, C.O., Ward, R., Tubbs, R.S. and Loukas, M. (2012) Annular Pancreas: A Review of Its Molecular Embryology, Genetic Basis and Clinical Considerations. Annals of Anatomy, 194, 422-428. https://doi.org/10.1016/j.aanat.2012.04.006 
[17] Nakajima, J., Takahashi, H., Suda, K., Suzuki, S., Sato, S., Hayashi, Y. and Kawashima, H. (2015) A 15-Year Old Boy with Congenital Duodenal Stenosis Due to Food Impaction. Pediatric Emergency Care, 31, 132-134.

https://doi.org/10.1097/PEC.0000000000000354

[18] Vilakazi, M., Ismail, F., Swanepoel, H.M., Muller, E.W. and Lockhat, Z.I. (2014) Duodenal Obstruction Due to a Preduodenal Portal Vein. African Journal of Paediatric Surgery, 11, 359-361. https://doi.org/10.4103/0189-6725.143176 